\title{
Potential error in density profile measurements for wood composites
}

\author{
Lauri Rautkari $^{{ }^{*}}$, Frederick A. Kamke ${ }^{2}$, Mark Hughes ${ }^{1}$ \\ ${ }^{1}$ Helsinki University of Technology, Department of Forest Products Technology, Espoo, \\ Finland \\ ${ }^{2}$ Oregon State University, Department of Wood Science and Engineering, Corvallis, USA
}

* Corresponding author.

Helsinki University of Technology, Forest Products Technology, P.O.Box 6400, 02015 TKK, Finland

E-mail: lauri.rautkari@tkk.fi

\begin{abstract}
The vertical density profile of wood-based composites is often measured using X-ray densitometry. During preliminary studies, in which the density profiles of wood composites with discrete layers of varying density were measured, it was observed that the absolute density values of the layers were incorrect when compared to gravimetric measurements of the individual layers. This is due the recommended calibration process of the $\mathrm{X}$-ray densitometer, which uses the overall density of the composite to determine the X-ray attenuation factor. The severity of the error increases with the difference between minimum and maximum density in the profile.
\end{abstract}

\section{Introduction}

Common industrial practice for the manufacture of wood composites, such as particleboard and MDF, is to routinely measure the density profile through the thickness, which is called "vertical density profile" or VDP. Instruments for VDP measurement use either gamma ray attenuation or X-ray attenuation. Instrument calibration is required, which is calculated from a reference specimen and the gravimetric determination of specimen density. The shape of the VDP is useful for quality control purposes and analysis of mat formation and hot-pressing operations. Maximum and minimum density values are known to relate to 
composite properties, such as bending modulus, surface hardness, and internal bond strength. However, the calibration procedure, while simple, may cause error in the VDP measurement. Recent investigation of a wood composite with discrete layers revealed a significant error in the VDP. This error is likely present in the routine measurements made by manufacturers depending on the severity of the VDP.

\section{Materials and methods}

Clear specimens having the following dimensions $126 \mathrm{~mm}$ (longitudinal), $50 \mathrm{~mm}$ (tangential) and $6 \mathrm{~mm}$ (radial) were prepared from the sapwood of air dried 11year old plantation-grown hybrid poplar (Populus deltoides x Populus trichocarpa L.). The hybrid poplar had an oven-dry density of $0.36 \mathrm{~g} / \mathrm{cm}^{3}$. The specimens were subsequently conditioned for at least 2 months in a conditioning chamber set at RH $65 \%$ and $20^{\circ} \mathrm{C}$ to an equilibrium moisture content (EMC) of $12.9 \%$.

Selected specimens were modified by a viscoelastic thermal compression (VTC) process designed to compress and densify the wood material. The process is carried out in a pressurized reaction vessel and utilizes only heat and steam. No chemicals are added. Further details can be found in Kutnar et al. (2009) and Kamke and Rautkari, (2009). The specimens were compressed to a target thickness of $1.5 \mathrm{~mm}$, corresponding to a density of $1.18 \mathrm{~g} / \mathrm{cm}^{3}$. Just after compression, the moisture content of the specimen modified by the VTC process ("VTC specimen") was $1.0 \%$ and after 1 month conditioning $\left(\mathrm{RH} 65 \%, 20{ }^{\circ} \mathrm{C}\right)$ the EMC was $4.1 \%$.

The VDP of the VTC specimen was measured using an X-ray densitometer (QMS, Model QDP-01X). Prior to scanning, the specimens were machined to dimensions of $50 \mathrm{~mm} \times 50 \mathrm{~mm} \times$ thickness, the external dimensions and weight of the specimens measured, and the density calculated. The density calculated from the weight and dimensions of the specimen was required to calibrate the QMS instrument. Density was measured in the QMS instrument at intervals of $0.04 \mathrm{~mm}$ through the thickness of the compressed wood. In addition to the VTC specimen, the density profile of an unmodified hybrid poplar specimen 50x50x18 mm (longitudinal $\mathrm{x}$ tangential $\mathrm{x}$ radial) was also measured. Both the modified and 
unmodified materials had been conditioned at $65 \% \mathrm{RH}$ and $20{ }^{\circ} \mathrm{C}$ for at least 1 month prior to measurement.

Following X-ray scanning the VTC specimens were glued on to the surfaces of the unmodified hybrid poplar using an epoxy adhesive (Devcon S-31/31345, ITW Performance Polymers) and clamped under a pressure of $1.8 \mathrm{MPa}$ for a period of 10 minutes. The dimensions and weight of this "composite" board (Fig. 1) were measured and its density calculated immediately after gluing. The VDP of the composite was measured as described above.

\section{Results and discussion}

The density of hybrid poplar modified by VTC was found to be $1180 \mathrm{~kg} / \mathrm{m}^{3}$ when calculated from the measured weight and dimensions of the specimen. The density of untreated wood measured in the same way was found to be $315 \mathrm{~kg} / \mathrm{m}^{3}$. Fig. 2a shows the density profiles of the VTC specimens together with the untreated wood, measured separately by X-ray densitometry, but combined together in one composite image. The VDP of the glued composite is also shown. The key point to note here is that the VDP of the treated and untreated wood specimens were measured separately and the densitometer was calibrated for each scan. As may be seen, the density values are the same for the untreated wood regardless whether it was measured separately or whether it was measured as part of the composite. However, for the thin sections of densified wood, the density values are significantly lower (about 5\%) when measured in the form of a composite. This is due to the way in which the X-ray densitometer is calibrated.

The instrument calibration procedure gives an average mass absorption coefficient (x-ray attenuation factor) for the whole of the specimen being measured. The procedure uses one specimen as a reference, which is scanned to collect X-ray attenuation data at predetermined increments through the thickness. An average mass absorption coefficient is then calculated such that the average density of the scan equals the gravimetrically-determined density of the whole specimen. More details about X-ray densitometry of wood composites are presented by Chen et al. (2009). 
The mass absorption coefficients / densities were $0.267 \mathrm{~cm}^{2} / \mathrm{g} / 1.18 \mathrm{~g} / \mathrm{cm}^{3}, 0.287$ $\mathrm{cm}^{2} / \mathrm{g} / 0.31 \mathrm{~g} / \mathrm{cm}^{3}$ and $0.284 \mathrm{~cm}^{2} / \mathrm{g} / 0.45 \mathrm{~g} / \mathrm{cm}^{3}$ for VTC wood, untreated wood and composite, respectively. These values were obtained as part of the calibration process. The coefficients of the untreated wood and the composite are similar; however, the coefficient of the VTC wood differs significantly. There is an inverse linear relationship between density and mass absorption coefficient $\left(\mathrm{R}^{2}=\right.$ 0.999). Because VTC wood represented a relatively small volume fraction in the composite, it had little affect on the mass absorption coefficient calculation. Therefore, when there are thin layers of very different density wood materials in the composite, density values in these layers will have an error when measured by $\mathrm{X}$-ray attenuation. Fig $2 \mathrm{~b}$ shows the VDP of the composite using the calibration coefficient for the whole specimen (Table 1, "Composite") and VDP of the same composite, using the calibration coefficient of the VTC wood. The VDP has been shifted upwards, with the density values for the VTC wood being the same level as when measured separately (Fig 2a.). However, there is now also a shift in the density values of untreated wood. This means that it is possible to choose the calibration coefficient for that part of the composite where more accurate values are needed. These observations raise the possibility of errors in VDP measurements of materials where there are large differences in density (e.g. particleboard and MDF). Finally, the epoxy can also be seen to have an influence on the density profile. The epoxy glue lines are seen as peaks in Figs $2 a$ and $2 b$ and adhesive penetration into the untreated wood as a shoulder between the untreated wood and the VTC wood.

\section{References}

Chen S, Liu X, Fang L, Wellwood R (2009) Digital X-ray analysis of density distribution characteristics of wood-based panels. Wood Sci Technol DOI 10.1007/s00226-009-0256-3.

Kutnar A, Kamke FA, Sernek M (2009) Density profile and morphology of viscoelastic thermal compressed wood. Wood Sci Technol 43:57-68.

Kamke FA, Rautkari L (2009) Modified wood veneer for structural applications. In: Proc. 4th International Symposium on Veneer Processing and Products (ISVPP), Espoo, Finland, p. 207-212.

Fig. 1. VTC and untreated wood composite. Surface layers are VTC wood.

Fig. 2. (a) Density profile of VTC wood specimens and untreated wood measured with densitometer separately (grey line) and density profile of composite (black line). (b) Density 
profile of composite (black line) using calibration coefficient for whole specimen, and density profile of composite (grey line) using calibration coefficient of only VTC wood.

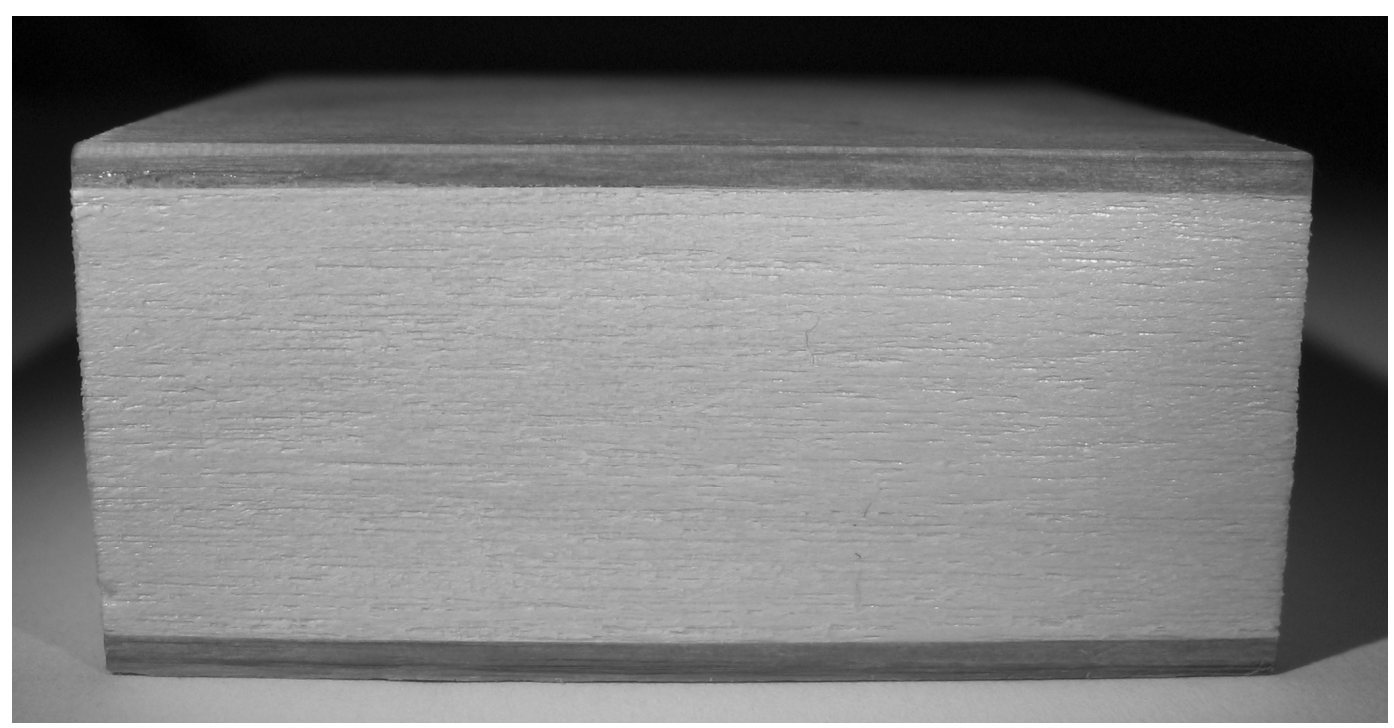

Abb. 1 Holzverbundwerkstoff aus unbehandeltem Holzwerkstoff mit thermogepressten Deckschichten (VTC)

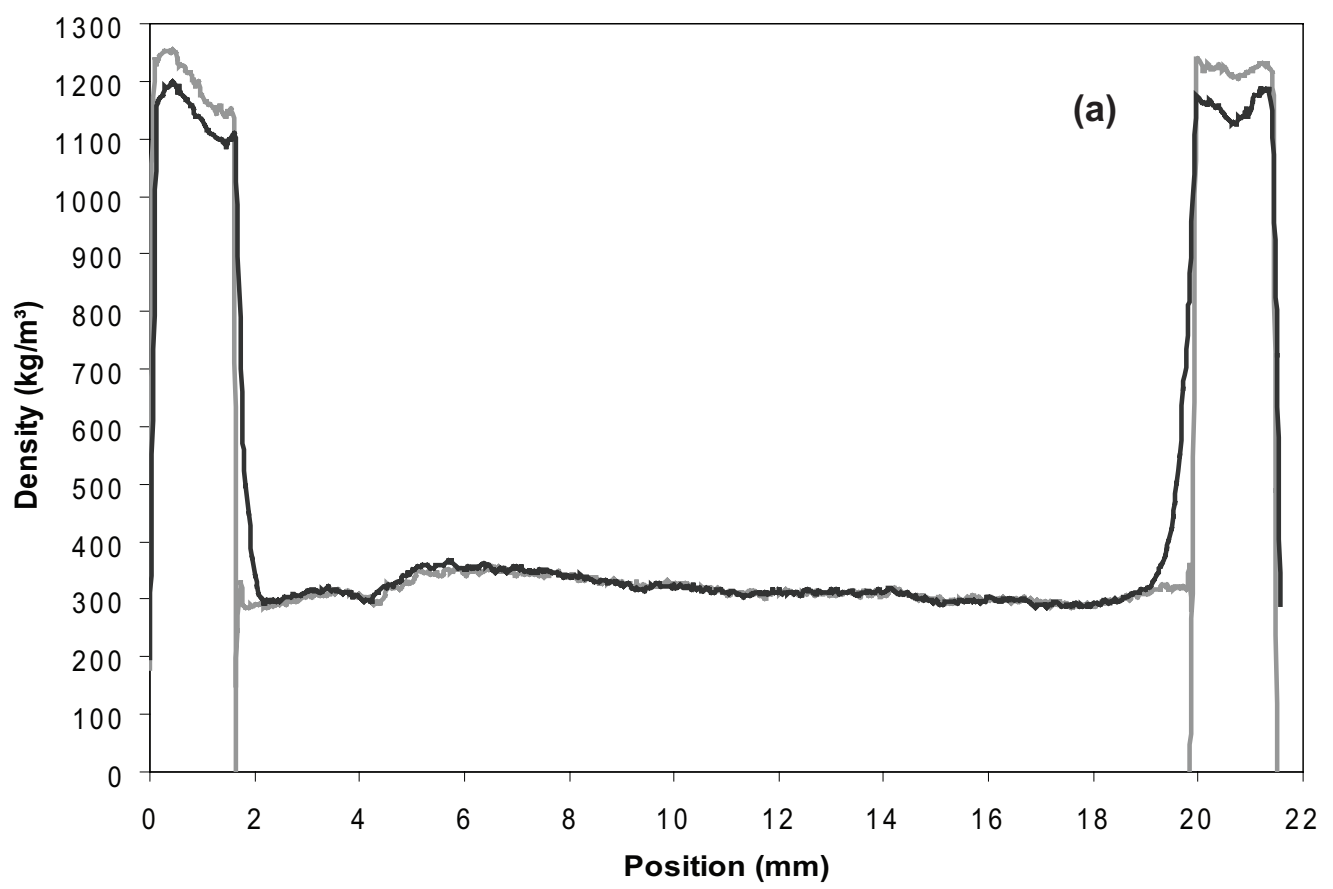

(a) 


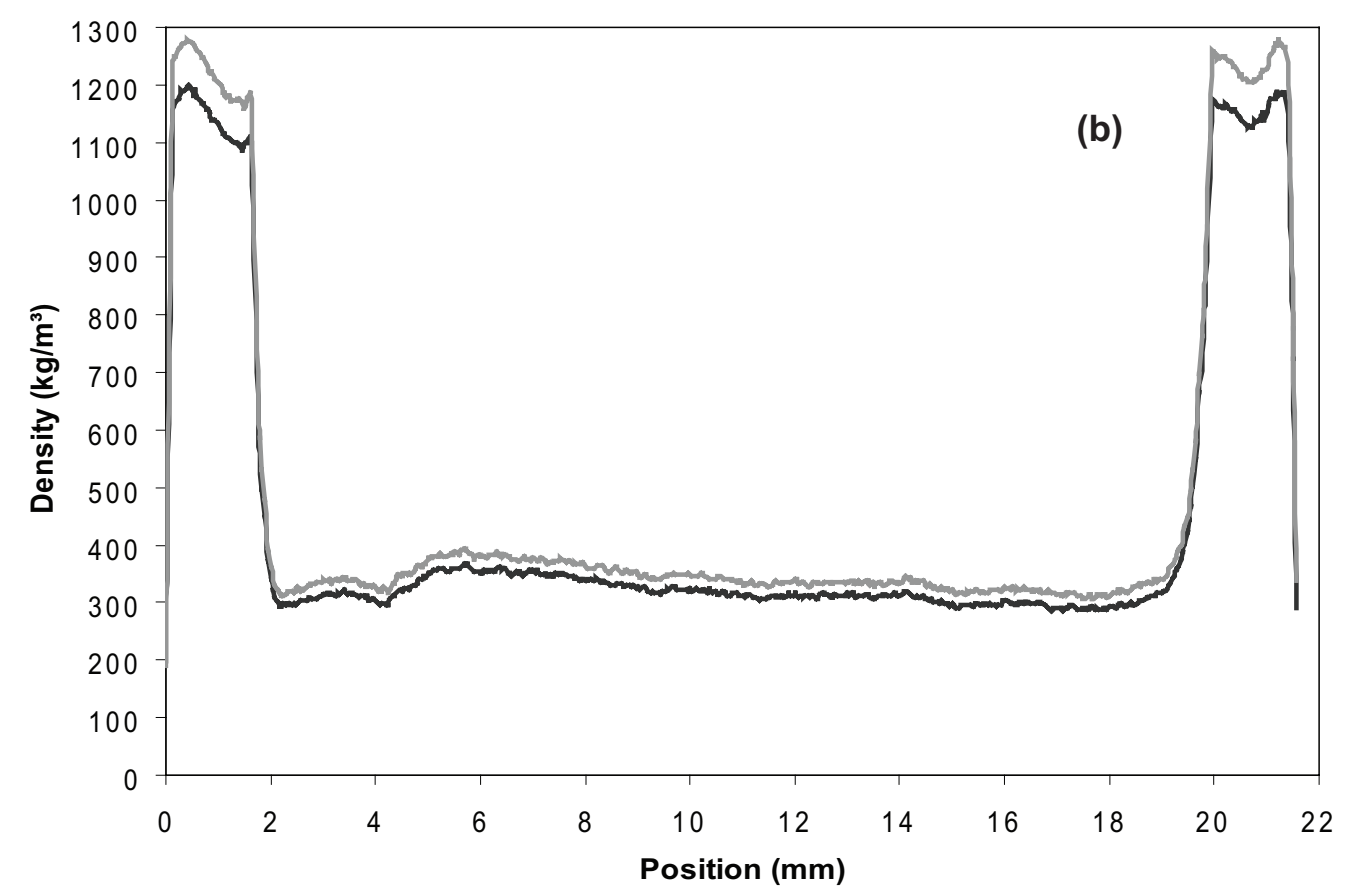

(b)

Abb. 2 (a) Dichteprofil des Holzverbundwerkstoffes. VTC-Deckschichten und unbehandelte Mittelschicht getrennt bestimmt (graue Kurve). Dichteprofil am Gesamtprüfkörper bestimmt (schwarze Kurve). (b) Dichteprofil des Gesamtprüfkörpers mit Kalibrierung am Gesamtprüfkörper (schwarze Kurve) und Kalibrierung nur an der VTC-Deckschicht (graue Kurve) 